AperTO - Archivio Istituzionale Open Access dell'Università di Torino

\title{
Arbuscular mycorrhizal fungal community differences among European long-term observatories
}

\section{This is the author's manuscript}

Original Citation:

Availability:

This version is available http://hdl.handle.net/2318/1622925

since 2017-01-23T21:24:54Z

Published version:

DOI:10.1007/s00572-016-0753-9

Terms of use:

Open Access

Anyone can freely access the full text of works made available as "Open Access". Works made available under a Creative Commons license can be used according to the terms and conditions of said license. Use of all other works requires consent of the right holder (author or publisher) if not exempted from copyright protection by the applicable law. 


\title{
Arbuscular mycorrhizal fungal community differences among European long-term observatories
}

\author{
M.-L. Bouffaudd ${ }^{1,2} \&$ C. Bragalini ${ }^{3,4}$ \& A. Berruti ${ }^{5}$ \& M. Peyret-Guzzon ${ }^{1} \&$ S. Voyron $^{3}$ \&

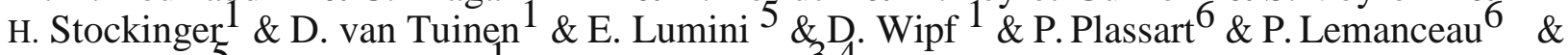 \\ I. Bianciotto ${ }^{5}$ \& D. Redecker ${ }^{1}$ \& \&. Girlanda 3,4
}

\begin{abstract}
Arbuscular mycorrhizal fungal (AMF) communi- ties have been demonstrated to respond to a variety of biotic and abiotic factors, including various aspects of land manage- ment. Numerous studies have specifically addressed the im- pact of land use on AMF communities, but usually have been confined to one or a few sites. In this study, soil AMF assem- blages were described in four different long-term observato- ries (LTOs) across Europe, each of which included a site- specific high-intensity and a low-intensity land use. AMF communities were characterized on the basis of 454 sequenc- ing of the internal transcribed spacer 2 (ITS2) rDNA region. The primary goals of this study were (i) to determine the main
\end{abstract}

M.-L. Bouffaud and C. Bragalini contributed equally to the work.

Electronic supplementary material The online version of this article (doi:10.1007/s00572-016-0753-9) contains supplementary material, which is available to authorized users.

* D. Redecker dirk.redecker@inra.fr

* M. Girlanda mariangela.girlanda@unito.it

${ }^{1}$ Agroécologie, AgroSup Dijon, CNRS, INRA, Univ. Bourgogne Franche-Comté, F-21000 Dijon, France

2 Present address: Helmholtz Center for Environmental Research - UFZ, Halle, Germany, German Centre for Integrative Biodiversity Research (iDiv), Leipzig, Germany

3 Department of Life Sciences and System Biology (DBios), University of Torino, 25 Viale Mattioli, 10125 Torino, Italy

4 Université Claude Bernard Lyon1, Lyon, France

5 CNR-Istituto per la Protezione Sostenibile delle Piante, UOS Turin (CNR-IPSP), Torino, Italy

6 Agroécologie, AgroSup Dijon, INRA, Univ. Bourgogne Franche-Comté, F-21000 Dijon, France 
factors that shape AMF communities in differentially man- aged sites in Europe and (ii) to identify individual AMF taxa or combinations of taxa suitable for use as biomarkers of land use intensification. AMF communities were distinct among LTOs, and we detected significant effects of management type and soil properties within the sites, but not across all sites. Similarly, indicator species were identified for specific LTOs and land use types but not universally for high- or low- intensity land uses. Different subsets of soil properties, includ- ing several chemical and physical variables, were found to be able to explain an important fraction of AMF community var- iation alone or together with other examined factors in most sites. The important factors were different from those for other microorganisms studied in the same sites, highlighting partic- ularities of AMF biology.

Keywords Arbuscular mycorrhizal fungi · Long-term observatories · 454 pyrosequencing · ITS2 · Soil management intensity

\section{Introduction}

Arbuscular mycorrhiza is a widespread mutualistic symbiosis between $80 \%$ of land plants (Smith and Read 2008) and fungi from the phylum Glomeromycota, originated at least 460 mil- lion years ago (Redecker et al. 2000). Only 250 species of Glomeromycota have been described based on spore morphol- ogy, which is a relatively small number considering their global geographic distribution and numerous potential plant hosts; nevertheless, they have an important role in ecosystem functioning.

Arbuscular mycorrhizal fungi (AMF) transfer phosphorus and other mineral nutrients from soil to plants, thereby im- proving plant growth, in exchange of host photosynthates 
(Drigo et al. 2010). They can confer plant pathogen protection (Azcón-Aguilar and Barea 1997; Zhang et al. 2009), as well as improve plant tolerance to heavy metal contaminants (Hildebrandt et al. 2007) and drought (Augé 2001; Li et al. 2013). Various ecosystem services are linked to the numerous functions provided by AMF, such as their ability to increase plant productivity (van der Heijden et al. 1998; Lekberg and Koide 2005), their influence on carbon, phosphorus and nitro- gen cycles (Fitter et al. 2011), and their maintenance of soil structure and stability (Mummey and Rillig 2006). These dis- tinct functional properties are often provided by different AMF species and isolates (Fitter et al. 2005; van der Heijden and Scheublin 2007; Hoeksema et al. 2010). Reflecting the important role played by local AMF communities in determin- ing plant growth, and because of the current environmental threats to AMF diversity (Turrini and Giovannetti 2012), there is increasing interest in describing and explaining the distribu- tion of AMF diversity in human-dominated landscapes (Moora et al. 2014).

At the regional and local scale, AMF communities have been demonstrated to respond to a variety of biotic and abiotic factors, including various aspects of land management that modify the physical and chemical characteristics of the soil and the plant cover/composition. Potential determinants of AMF diversity and community composition are the identity of the host plants (van der Heijden et al. 1998; Bainard et al. 2011; Liu et al. 2012), soil type (Verbruggen et al. 2012; Hazard et al. 2013), soil pH (An et al. 2008; Dumbrell et al. 2010a; Hazard et al. 2013; Bainard et al. 2014; Xiang et al. 2014), soil texture and nutrient concentrations (Lekberg et al. 2007; Fitzsimons et al. 2008; Bai et al. 2009; Verbruggen et al. 2012; Moebius-Clune et al. 2013; Bainard et al. 2014; Xiang et al. 2014), and climate (Dumbrell et al. 2011; Hazard et al. 2013). Apart from these specific environmental factors, direct land use-related circumstances, such as tillage (which in- creases soil disturbance) or grazing (which removes above- ground plant biomass), also have been suggested as drivers of AMF community composition (e.g., Helgason et al. 1998; Oehl et al. 2010; Schnoor et al. 2011; Stockinger et al. 2014; Valyi et al. 2015). A high number of studies specifically have addressed the impact of agricultural practices and changes in land use on either the composition of AMF communities (e.g., van der Gast et al. 2011; Lin et al. 2012; Lumini et al. 2010; Verbruggen et al. 2012; Dai et al. 2013; Hazard et al. 2013; Morris et al. 2013; Moora et al. 2014; Xiang et al. 2014; Valyi et al. 2015) or individual taxa (Bainard et al. 2014; Jansa et al. 2014). Experimental studies, however, usually are confined to one or a few sites, and therefore may have facilitated the identification of effects of specific agricultural practices at the expense of visibility of other (independent) effects such as soil type and geography (Jansa et al. 2014). Furthermore, to fully appreciate the extent of anthropogenic influence on AMF soil communities, the impact of management practicesshould be weighed against the background of the normal (e.g., seasonal, plant growth-related) fluctuations of AMF taxa un- der field conditions (Pereira et al. 2013).

As previously underlined by Jansa et al. (2014), soil qual- ity, health, and management history are extremely important factors for understanding and supporting the sustainable use of soils, but they can be difficult to quantify or define func- tionally. AMF are important contributors to soil function in agricultural as well as natural contexts. Due to the relatively low diversity of AMF taxa, different preferences of individual taxa for environmental properties, and their global distribu- tion, AMF therefore are promising candidates as bioindicators of land management legacies and soil quality degradation (Jansa et al. 2014).

This study was conducted within the framework of the European Union project EcoFINDERS, which had a major objective to analyze patterns of diversity of a broad range of soil microorganisms across Europe. Therefore, the same soil samples and DNA extracts from long-term observatories (LTOs) used here also were used to address the diversity of other microorganisms (Thomson et al. 2015), which is Bacteria, Archaea, and Fungi in general. On a larger scale, a transect of 54 sites across 
Europe was analyzed in that project (which included treatments from the four LTOs analyzed here) to analyze broad patterns of AMF distribution (Bouffaud et al. 2016).

In the present study, soil AMF assemblages were described in different LTOs, each of which included a high-intensity and a low-intensity land use that differed among the LTOs. High- intensity land uses analyzed previously were often associated with a reduction in AMF abundance and/or diversity (e.g., Van Geel et al. 2015; Verbruggen et al. 2015; Ciccolini et al. 2015; Spurgeon et al. 2013; Borriello et al. 2012; Lumini et al. 2010). AMF communities were characterized in spring and autumn 2011 on the basis of 454 sequencing of the internal transcribed spacer 2 (ITS2) rDNA region. At both the local and the broader (trans-regional) scale, the studied samples represented a diverse array of soil and environmental charac- teristics, being situated in different European climatic and geological zones. The primary goal of this study was (i) to determine the main factors that shape AMF community structure but also the abundance of individual AMF taxa in differ- entially managed sites in Europe and (ii) to identify individual AMF taxa or combinations of taxa suitable for use as bio- markers of land use intensification. Because the relative im- portance of the various drivers of AMF community composition may change at different spatial scales (Horn et al. 2014), comparative analyses of AMF communities and taxa distribu- tions were performed at both the continental (among-LTO) and local (intra-LTO) scales.

We specifically asked the following: (1) Does land use intensification have a larger impact compared to other envi- ronmental filters in structuring AMF communities at 
individual field sites and across Europe? (2) Is the impact of land use intensification on AMF communities mediated by changes in soil physicochemical features? (3) Are there Buniversal $\wedge$ AMF indicators of land use changes across different European geographic and climatic regions?

Materials and methods

Sites and soil sampling

In this study, four LTOs distributed over Western Europe, representing eight different land uses (two per LTO, listed in Table 1; see also Supporting Information S1 in Thomson et al. (2015)) in a range of climatic zones and soil types, were com- pared as part of the European project EcoFINDERS (http://www.ecofinders.eu/). At each LTO, two land use intensities were analyzed: low (L) or high (H) intensity (Table 1).

At the LTO situated in Berchidda, Sardinia, Italy $\left(40^{\circ} 49^{\prime} \mathrm{N}, 9^{\circ} 17^{\prime \prime} \mathrm{E}\right)$, two different levels of intensity of Mediterranean agricultural land management were ana- lyzed: (i) an intensively managed grassland (Berchidda

$\mathrm{H})$ which is grazed and mown every 1-5 years for fod- der production (Avena sativa, Lolium multiflorum, Trifolium subterraneum, Trifolium michelianum, etc.) and (ii) a long-term (>80 years) abandoned grassland (Berchidda L) which has naturally been colonized by cork oaks (Quercus suber). The soil is predominantly Typic Dystroxerept. Further site details have been re- ported previously by Orgiazzi et al. (2012), Seddaiu et al. (2013), and Bagella et al. (2014).

At the LTO in the Yorkshire Dales National Park near Lancaster, United Kingdom $\left(54^{\circ} 18^{\prime} \mathrm{N}\right.$, $2^{\circ} 10^{\prime} \mathrm{W}$ ), two levels of fertilization of mesotrophic grasslands were compared: (i) Bimproved, ${ }^{\wedge} \mathrm{NPK}-$ fertilized $(>100 \mathrm{~kg}$

N/ha/year), Lolium perenne-Cynosurus cristatus grass-

lands (Lancaster $\mathrm{H}$ ) with high agricultural value and low floristic diversity, intensively managed, and (ii) traditionally managed, non-fertilized grasslands (Lancaster L) with a high floristic diversity. These unim- proved grasslands are species-rich Anthoxanthum odoratum-Geranium sylvaticum meadows.

Our sampling at the LTO site at Lusignan, France $\left(46^{\circ} 24^{\prime} \mathrm{N}, 0^{\circ} 7^{\prime} \mathrm{E}\right)$ included two cultural practices: (i) a permanent culture rotation (Lusignan $\mathrm{H}$ ) and (ii) a per- manent grassland (Lusignan L) with nitrogen amend- ment ( $\mathrm{N}$ fertilizer). In this site, four large experimental blocks (field replicates) are divided into five plots per block, one for each treatment. In this study, replicates from two treatments were analyzed: permanent culture (high intensity) and permanent grassland (low intensity), resulting in eight samples.

The LTO in the National Park of Veluwe, Netherlands $\left(52^{\circ} 03^{\prime} \mathrm{N}, 5^{\circ} 45^{\prime} \mathrm{E}\right)$, is a chronosequence comprising plots abandoned from agricultural use which have been turned into semi-natural grasslands. The abandoned fields are subject to extensive natural grazing by wild horses, deer, wild boar, and small mammals. In this study, two levels of abandoned agricultural lands were analyzed: (i) a re- cently abandoned grassland (6 to 14 years, Veluwe H) and (ii) a long-term abandoned grassland (more than 25 years) (Veluwe L). Further details concerning the site can be found in Kardol et al. (2005).

Geographic distances between LTOs (inter-LTO distances) were between 597 and 1715 km, and within LTOs (between plots with different level of intensity) were between 0.066 and 
$0.400 \mathrm{~km}$. Soil samples of a specific land use were collected at $100 \mathrm{~m}$ distance from each other.

A minimum of three spatially independent soil samples were sampled from all land uses in spring and autumn 2011. Each sample was a composite of five soil cores of $5 \mathrm{~cm}$ diam- eter and $20 \mathrm{~cm}$ depth. Soil samples were sieved to $4 \mathrm{~mm}$ and stored at $-40^{\circ} \mathrm{C}$ at the GenoSol platform (http://www2.dijon.

inra.fr/plateforme_genosol/en) prior to physicochemical and microbiological analyses. A video of this sampling procedure and the soil processing can be found at https://www.youtube.com/watch?v=_k7BEInBXEc.

Table 1 Description of the four

long-term observatories Long-term observatories

Description

\begin{tabular}{lll}
\hline & Latitude & Longitude (LTOs) \\
Lusignan (France) & Permanent culture rotation (H) & $46.413106 \mathrm{~N}$ \\
& & $0.121325 \mathrm{E}$
\end{tabular}

Permanent grassland with nitrogen amended (L)

$46.41223 \mathrm{~N}$

$0.11831 \mathrm{E}$

Berchidda (Sardinia, Italy)

Intensive

grassland $(\mathrm{H})$

$40.81604 \mathrm{~N}$

$9.29237 \mathrm{E}$

Wooded pasture (L)

$40.81782 \mathrm{~N}$

$9.28785 \mathrm{E}$

Lancaster (UK) Improved grassland (H)

$54.30896 \mathrm{~N}$

2.07077 W

Unimproved grassland (L) $\quad 54.3089 \mathrm{~N}$

2.08186 W Veluwe (Netherlands) Short term

abandoned grassland $(\mathrm{H})$

$52.00280 \mathrm{~N}$

$5.75180 \mathrm{E}$

Long term abandoned grassland (L) $52.02917 \mathrm{~N}$

$5.80108 \mathrm{E}$ 
Soil physicochemical analyses

Several soil properties were measured by the Laboratoire d'analyse des sols d'Arras of INRA (http://www.lille.inra. fr/las). Total nitrogen (N), total carbon (C), and organic matter contents were measured after combustion at $1000{ }^{\circ} \mathrm{C}$. Phosphorus (P) content was determined by NaHCO3 $(0.5 \mathrm{M}, \mathrm{pH}$ 8.5) extraction (Olsen 1954). The cation exchange capac- ity (CEC) was determined by extraction with Co(NH3)6Cl3 (Ciesielsky and Sterckeman 1997). Exchangeable cations (Ca, Mg, Na, K, Fe, Mn, and Al) were extracted using cobaltihexamine and determined by inductively coupled plas- ma spectrometry-atomic emission spectrometry (ICP-AES). Soil pH was measured on soil slurries (1:5 deionized water/soil).

\section{DNA extraction and purification}

Total metagenomic DNA was extracted from $1 \mathrm{~g}$ of each sam- ple using the ISOm protocol, described in Plassart et al. (2012). DNA extracts were purified in two steps. First, DNA was loaded onto polyvinylpolypyrrolidone (PVPP) minicolumns (BIORAD, Marne-la-Coquette, France) and centrifuged at $1000 \mathrm{~g}$ for $2 \mathrm{~min}$ at $10^{\circ} \mathrm{C}$. The eluate was then purified using the Geneclean turbo kit (QBiogene, Illkirch, France). Purified DNA was quantified using the Picogreen kit (Invitrogen, Saint Aubin, France) according to the manufac-

turer's instructions and stored at $-80^{\circ} \mathrm{C}$.

\section{PCR amplification and pyrosequencing}

Nested PCRs were performed on all samples, and each DNA extract was amplified in three replicates. The first PCR was performed using 0.4 U of Phusion High Fidelity DNA poly- merase (Thermo Fisher Scientific, Courtaboeuf, France), $1 \times$ Phusion HF buffer, $0.5 \mu \mathrm{M}$ of the primers SSUmCf and LSUmBr (Krüger et al. 2009), $0.2 \mathrm{mM}$ of each dNTPs, and $1 \mu \mathrm{l}$ of genomic DNA, in a final volume of $20 \mu \mathrm{l}$. The PCR conditions used were $5 \mathrm{~min}$ at $99^{\circ} \mathrm{C}$, 35 cycles of $10 \mathrm{~s}$ at $99{ }^{\circ} \mathrm{C}, 30 \mathrm{~s}$ at $63{ }^{\circ} \mathrm{C}$, and $1 \mathrm{~min}$ at 72 ${ }^{\circ} \mathrm{C}$, followed by $\quad 10 \mathrm{~min}$ at $72{ }^{\circ} \mathrm{C}$, using an Eppendorf Mastercycler epgradient S (VaudauxEppendorf, Schönenbuch, Switzerland). Each PCR product was checked on agarose gel (presence of a single band with the correct length) and diluted at 1/50 with water to use as template in the nested PCR. The nested PCR was done using $1 \mathrm{U}$ of Phusion High Fidelity polymerase, $1 \times$ HF buffer,

$0.5 \mu \mathrm{M}$ of the ITS3m and ITS4 (White et al. 1990) primers with 5 bp barcodes (Table S1), $0.2 \mu \mathrm{M}$ of each dNTPs, and $2 \mu \mathrm{l}$ of diluted PCR product, in a total volume of $50 \mu \mathrm{l}$. ITS barcoding primers that are commonly used to describe the whole fungal community of soil are considered sub-optimal for AMF (Stockinger et al. 2010) or have substantial mis- matches (Ihrmark et al. 2012), potentially generating misleading ecological conclusions. Therefore, ITS3m (GCATCGATGAACAACGYAG, Bouffaud et al. 2016) was designed as a modification of ITS3 (White et al. 1990) based on an extensive alignment of Glomeromycota ITS region se- quences, to better allow reliable amplification from this phy- lum without necessarily discriminating against other fungi. Phylum-level specificity in our system was conferred by the primers in the first PCR reaction. PCR conditions were $30 \mathrm{~s}$ at $98{ }^{\circ} \mathrm{C}, 30$ cycles of 10 $\mathrm{s}$ at $98{ }^{\circ} \mathrm{C}, 30 \mathrm{~s}$ at $64{ }^{\circ} \mathrm{C}$, and $20 \mathrm{~s}$ at $72{ }^{\circ} \mathrm{C}$, followed by $10 \mathrm{~min}$ at $72{ }^{\circ} \mathrm{C}$, in an Eppendorf Mastercycler epgradient S. PCR products were checked on agarose gel; the three replicates of each sample were pooled and purified using the High Pure PCR Product Purification Kit (Roche Applied Science, Meylan, France) following the man- ufacturer's instructions. After quantification using 
Picogreen, the purified PCR products were mixed equimolarly to prepare sequencing libraries. The libraries were sent to Beckman Coulter Genomics (Grenoble, France) for sequencing using 454 GS FLX technology. The raw data were deposited in the Sequence Read Archive (http://www.ncbi.nlm.nih.gov/sra) under the Bioproject SRP075244.

Sequence and data analysis

The sequences were demultiplexed according to their multi- plex identifier (MID) using the sffinfo command of Mothur

v.1.30.2 (Schloss et al. 2009), allowing one mismatch per MID. The raw flowgrams were filtered using the trim.flows command to a minimum flowgram length of 360 cycles and were truncated at 720 cycles. Sequences from forward and reverse primers were sorted according to their primer se- quences using the trim.seqs and split.groups commands of mothur, allowing 2 mismatches per sequence, and then, se- quences from reverse primers were converted into their re- verse complements. Sequences were checked using Fungal ITS extractor v.2 (Nilsson et al. 2010), and non-ITS sequences were removed. The resulting sequences were clustered using Uclust (Edgar 2010) at 97\% identity threshold to create oper- ational taxonomic units (OTUs), and singletons were exclud- ed from further analysis.

For taxonomic assignment, firstly, a Blast search against UNITE database (Abarenkov et al. 2010) was performed in

order to eliminate non-Glomeromycota sequences and se- quences for which the best Blast hit had an e-value $>1.10^{-5}$.

Secondly, the EPA algorithm of RAxML v8.0 (Berger et al. 2011) was used to correct and improve the taxonomic assign- ment of the OTUs and define BMolecular Taxa^ (MTs) of Glomeromycota.

To analyze the whole dataset (4 LTOs $\times 2$ intensity levels $\times 2$ seasons), a subsampling of 800 reads per sample was performed before comparisons, and nine samples out of 60 with less than 800 sequences were excluded from the anal- yses (Fig. S1). Although this sequencing depth could not 
assess the full extent of AMF diversity, previous studies showed that this depth of analysis is sufficient to describe differences in microbial community composition, even for taxa having high species diversity (Fierer et al. 2013; Thomson et al. 2015). Differences in AMF community com- position also were analyzed separately for each LTO, to eval- uate specifically the impact of the level of land use intensity. For these analyses, LTO-specific subsamplings of the se- quencing data were performed, yielding 850, 1550, 1200, and 2100 reads per sample for Lusignan, Berchidda, Lancaster, and Veluwe, respectively.

Jaccard distances between AMF communities (based on presence/absence data matrix) were calculated and visualized in non-metric multidimensional scaling (NMDS) plots using the ggplot2 package (Wickham 2009) of R v3.2.1 (R development core team 2013). The effects of LTO, season, land use intensity, and land use type factors on AMF commu- nity composition were evaluated using permutational multi- variate analysis of variance (PERMANOVA, 1000 permuta- tions, alpha $=0.05$ ). The multivariate homogeneity of group dispersions was assessed by means of the betadisper and permutest (with 999 permutations, alpha $=0.05$ ) functions in the $\mathrm{R}$ package vegan (Oksanen et al. 2013). In addition, be- cause AMF abundance previously has been documented to respond sometimes strongly and with a phylogenetic basis to land use intensity and season, we adopted a Chi-square test in order to characterize differential distributions between the two levels of land use intensity and between the two sampling time points (season) of each Glomeromycota order found.

The indicator species analysis (Dufrene and Legendre 1997) was carried out using the indicspecies package (De Cáceres and Legendre 2009) in R v3.2.1, in order to assess if and which individual taxa or combinations of two taxa were associated with a particular land use type. Joint occurrences of two taxa were used to calculate the predictive indicator value more correctly than by taking the two taxa independently, as suggested by De Cáceres et al. (2012). This procedure also is recommended because a given sample group may have no individual indicator species even if its samples have a com- munity composition that is clearly distinct from the samples of other sample groups.

Data obtained from basic soil characteristic (e.g., pH, soil texture, organic matter content, and macronutrient content; see Table S2) measurements were submitted to a principal com- ponent analysis (PCA) using Euclidean distance. In addition, soil chemical properties were included in a second matrix in NMDS analysis to identify which environmental variables were significantly linked to ordination of the AMF communi- ty (using the envfit function of the R vegan package; Oksanen et al. 2013).

To quantify the relative contribution of soil parameters, land use intensity, and season upon soil AMF communities, variance partitioning was performed. Soil variables that best explained the AMF community structure were forward- selected in an effort to search for parsimony among the explanatory variables and to reduce the collinearity of the model using the ordistep function ( $\mathrm{R}$ vegan package, Oksanen et al. 2013). Subsequently, the varpart (R vegan package, Oksanen et al. 2013) function was used to determine the amount of variance in AMF communities that could be explained by forward-selected soil conditions, land use intensity, and sam- pling season.

\section{Results}

Quality-filtered sequences obtained by 454 GS FLX pyrose- quencing clustered in 5920 OTUs, including 1023 singletons. Singletons were removed to avoid overestimation of AMF diversity. A total of $67 \%$ of the sequences corresponded to Glomeromycota, $13.5 \%$ to unknown fungi, $9.6 \%$ to Basidiomycota, $8.7 \%$ to Ascomycota, $1 \%$ to Zygomycota, and $0.2 \%$ to others. A total of 324,734 
sequences were assigned to 57 Glomeromycota species-level molecular taxa (Fig. 1, Table S3) belonging to all four Glomeromycota orders (Glomerales, Archaeosporales, Diversisporales, and Paraglomerales).

No significant differences of molecular species richness or Shannon indices were found among LTO sites, land use inten- sities, or sampling seasons (Table S4).

\section{Comparisons of AMF communities among LTOs}

PERMANOVA analyses showed significant differences of the AMF communities between LTO sites (Table 2; Table S5), which could be partly explained by the well-differentiated soil properties of the different LTOs (Fig. S2). About half of these molecular taxa were found in all four sites (Fig. 1).

For each LTO, the portion of sequences belonging to each of the four Glomeromycota orders (based on Schüßler and Walker 2010; Redecker et al. 2013) is reported in Table S6 and Fig. S3. The AMF communities of the LTOs showed

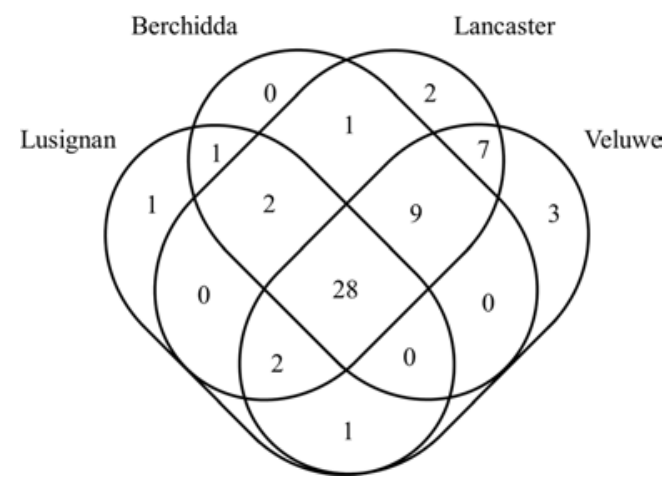

Fig. 1 Venn diagram of the number of molecular taxa specific to each LTO and shared among them 
Table 2 Results of PERMANOVA (999 permutations) based on the Jaccard distance matrix of the AMF communities (combined dataset: spring + autumn)

$$
\text { df } \quad \text { Pseudo-FR } R^{2} \quad P
$$

\begin{tabular}{lcccc}
\hline LTO & 3 & 6.850 & 0.27 & 0.001 \\
Season & 1 & 2.159 & 0.03 & 0.008 \\
Land use intensitv level & 1 & 1.271 & 0.02 & 0.184 \\
LTO $\times$ season & 3 & 2.218 & 0.09 & 0.001 \\
LTO $\times$ land use & 3 & 2.119 & 0.08 & 0.001 \\
Season $\times$ land use & 1 & 1.231 & 0.02 & 0.214 \\
\hline
\end{tabular}

Significant results $(P<0.05)$ are in italics

LTO long-term observatory

differences in their global composition on the order level: for instance, the Lusignan site was poor in Diversisporales se- quences relative to the others. In NMDS ordination, the sites showed some tendency for differentiation (Fig. 2). A much stronger separation was observed between the high- and lowintensity land use samples from Lusignan than among the other LTOs.

A significant effect of the sampling time (season) was de- tected on the AMF community structure (PERMANOVA, Table 2). These analyses also highlighted significant effects of the LTO alone and of the interaction between LTO and both season and land use intensification level on AMF community composition (PERMANOVA, Table 2). Such an effect could be biased, however, by the non-homogeneity of group disper- sions within the Lusignan and Berchidda LTO samples (Fig. S4). The NMDS plot graphically confirmed the strong non-homogeneity of the multivariate spread of the AMF com- munity in the $\mathrm{H}$ soil samples of the Lusignan LTO with respect to most of the remaining land uses (Fig. 2). The land use intensity level did not have a significant effect when the four LTOs were analyzed together (Table 2). However, the highly significant interaction between LTO and intensity factors sug- gests the presence of LTO-specific effects of land use intensi- fication (detailed in the next section). Lusignan $\mathrm{H}$ land use featured the lowest (albeit non-significantly so) richness and Shannon index values (Table S4).

\section{AMF communities within LTOs}

PERMANOVA analyses carried out on each LTO separately (Table 3) indicated a significant effect of land use intensity on the AMF community composition in the Lusignan, Berchidda, and Veluwe sites. However, the two levels of land use intensity exhibited non-homogeneous variances at the Lusignan LTO; therefore, the level of significance of the PERMANOVA might have been increased by this feature. 


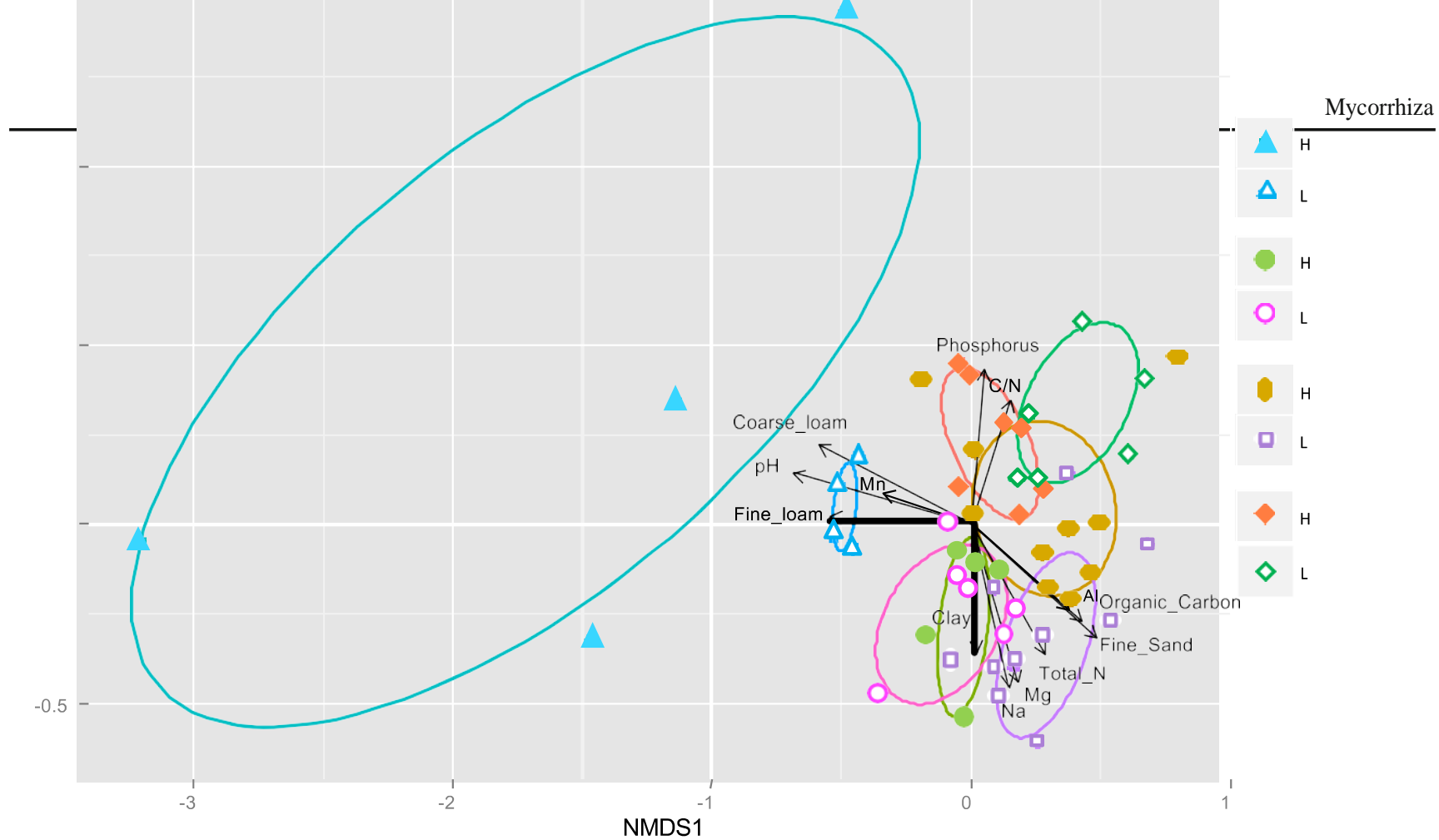

Fig. 2 Nonmetric multidimensional scaling (NMDS) ordination of AMF soil communities based on the Jaccard presence-absence distance matrix. Stress of the final NMDS solution was 0.184. Arrows correspond to 
significantly fitted environmental parameters in the ordination $(P<0.05$, Table S8). $H$ highintensity land use; $L$ low-intensity land use 
Table 3 PERMANOVA results (999 permutations) for AMF soil community comparisons performed for each long-term observatory

(Jaccard distance matrices of combined datasets:

spring + autumn)

\begin{tabular}{lllll}
\hline & & & & -2 \\
\hline Season & 1 & 3.3709 & 0.29 & 0.00 \\
Land use intensity & 1 & 2.2311 & 0.20 & 0.033 \\
$\quad$ Season $\times$ land use & 1 & 1.8601 & 0.16 & 0.09 \\
Berchidda & & & & \\
Season & 1 & 0.920 & 0.08 & 0.59 \\
Land use intensity & 1 & 1.786 & 0.16 & 0.04 \\
$\quad$ Seasnn $\times$ land use & 1 & 1.373 & 0.12 & 0.18 \\
Lancaster & & & & \\
Season & 1 & 1.943 & 0.10 & 0.01 \\
Land use intensity & 1 & 1.186 & 0.06 & 0.28 \\
$\quad$ Seasnn $\times$ land use & 1 & 0.695 & 0.04 & 0.79 \\
Veluwe & & & & \\
Season & 1 & 1.064 & 0.09 & 0.40 \\
Land use intensity & 1 & 1.851 & 0.15 & 0.04 \\
$\quad$ Season $\times$ land use & 1 & 0.510 & 0.04 & 0.89 \\
\hline
\end{tabular}

Significant results $(P<0.05)$ are in italics. Homogeneity of group disper- sions was tested with betadisper and permutest

a Significant $(P<0.05)$ heterogeneity of group dispersions

By contrast, land use intensity was not a significant factor for the Lancaster LTO, for which, instead, as also in Lusignan, season was found to have a significant effect.

At the three LTOs featuring a significant effect of the land use intensity (Lusignan, Berchidda, and Veluwe), such effects involved all Glomeromycota orders. By contrast, at the Lancaster site, significant land use intensity effects were only found for Diversisporales and Archaeosporales (Table S6). Season also significantly affected all Glomeromycota orders at all sites (Table S6). Differences particularly obvious be- tween land use intensities were shown for Archaeosporales in Lusignan, while Paraglomerales were present in a much stronger proportion of sequences in spring in Lusignan and Veluwe (Fig. S3), compared to the autumn sampling.

Indicator species for land use and intensity level

Indicator species analysis was carried out to test whether sin- gle AMF taxa or combinations of taxa could be found as being representative of a particular land use and/or group of land uses and/or land use intensity level. Effects of the season on AMF community composition were found only in Lancaster and Lusignan; however, seasonal effects on specific AMF taxa could not be ruled out in the other LTOs. For this reason, we computed the indicator species analysis on the spring and autumn datasets separately. Table 4 reports the taxa/ combinations of two taxa that yielded consistent results (IndVal.g $\geq 0.6, P<0.05$ ) in both spring and autumn, as we hypothesize that a good indicator should be found associated to the same group of land uses in both spring and autumn.

Three single taxa and nine combinations of two taxa were found in both seasons as being associated with a specific land use type or to more than one with a significant indicator value. No LTO-independent 
Effects of soil properties on AMF communities

The analyzed LTOs (Table 1) represent a range of soils with different physicochemical properties (Table S2, Fig. S2).

Table 4Results of indicator species analysis

\begin{tabular}{|c|c|c|c|c|c|c|}
\hline \multirow{2}{*}{ Land use } & \multirow{2}{*}{\multicolumn{2}{|c|}{ Indicator taxa (single combinations of }} & \multicolumn{2}{|l|}{ Spring } & \multicolumn{2}{|l|}{$\underline{\text { Autum }}$} \\
\hline & & & IndVal & $P$ & IndVal & $P$ \\
\hline \multirow[t]{5}{*}{ Lusignan low } & Archaeosporaceae & Septoalomus & 1 & 0.00 & 1 & 0.014 \\
\hline & Ambispora fennica & Septoqlomus sp.1 & 1 & 0.00 & 0.913 & 0.016 \\
\hline & Rhizophaqus sD.1 & Septoalomus sD.1 & 0.913 & 0.01 & 0.913 & 0.016 \\
\hline & Archaeosporaceae & Septoalomus & 0.913 & 0.01 & 0.845 & 0.025 \\
\hline & Claroideoalomus & Septoalomus sD.1 & 0.913 & 0.01 & 0.845 & 0.025 \\
\hline \multirow{4}{*}{ Lancaster high + low } & Glomus & & 0.894 & 0.00 & 0.837 & 0.013 \\
\hline & Acaulospora & Glomus & 0.894 & 0.00 & 0.837 & 0.013 \\
\hline & Archaeosporaceae & Glomus & 0.894 & 0.00 & 0.837 & 0.013 \\
\hline & Glomus & Glomus sD.1 & 0.894 & 0.00 & 0.837 & 0.013 \\
\hline Lusignan high + low & Septoqlomus & & 0.866 & 0.02 & 1 & 0.001 \\
\hline \multirow[t]{2}{*}{ All land uses excent } & Archaeosporaceae & & 1 & 0.00 & 0.979 & 0.03 \\
\hline & Archaeosporaceae & Glomeraceae & 1 & 0.00 & 0.979 & 0.03 \\
\hline
\end{tabular}

Indicator species values (IndVal.g, ranging from 0 to 1, with higher values indicating higher fidelity and specificity of the indicator species in relation to a given land use) and $P$ values (999 permutations) are reported. Only single taxa or combinations of two taxa consistent in the two seasons are reported 
Because soil properties did not change significantly between the two sampling campaigns (PERMANOVA; Table S5), analyses were run on the combined (spring + autumn) datasets. Soil properties differed significantly $(P<0.05)$ be- tween LTOs and were overall poorly affected by land use intensity (Table S5). Soil texture was sandy loam in Berchidda, silt loam in Lusignan, loamy sand in Veluwe, and clay loam in Lancaster. Organic carbon was high in Lancaster and low in Lusignan. The highest total nitrogen and phosphorous were found in Lancaster and Veluwe, re- spectively. All LTOs had acidic soil, with the exception of Lusignan, in which soil $\mathrm{pH}$ was sub-acidic. Soil fertility mea- sured as CEC was high in Lancaster, which had the highest calcium, magnesium, sodium, and potassium, and low in Veluwe, which had the lowest calcium, sodium, potassium, and manganese. Berchidda was the only LTO in which soil properties differed consistently between the two levels of land use intensity. Indeed, 12 out of 18 soil parameters differed statisticallybetween the intensive grassland $(\mathrm{H})$ and the wood- ed pasture land use (L; Table S7, Fig. S2). By contrast, in the case of the other LTOs, only two (fine loam and fine sand content for Lusignan) and four (clay, fine sand, P and Fe content for Lancaster and clay, P, Fe and Al content for Veluwe) parameters differed significantly between the two levels of land use intensity (Table S7).

Among environmental vectors significantly linked to the NMDS ordination space of AMF community composition (Fig. 2, Table S8), the most significant soil features $(P \leq 0.005$, Bonferroni corrected $P \leq 0.1)$ were several soil textural characteristics, $\mathrm{pH}$, organic $\mathrm{C}$, total $\mathrm{N}, \mathrm{Mg}$, and $\mathrm{Na}$ contents. The forward-selected soil variables differed depend- ing on the LTO (Table S9). No soil physicochemical variable was selected for the

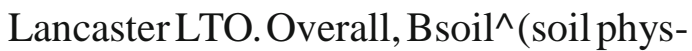
icochemical properties), Bintensity^ (the land use intensity level), and Bseason^^ (temporal variation) accounted for

Fig. 3 Partitioning of the variances of the AMF communities by explanatory variables. Bar plots represent the variance explained by soil variables (soil), land use intensity (intensity), sampling g.jme (season), two explanatory variables, all explanatory variables (shared), and the unexplained variance (unexplained)

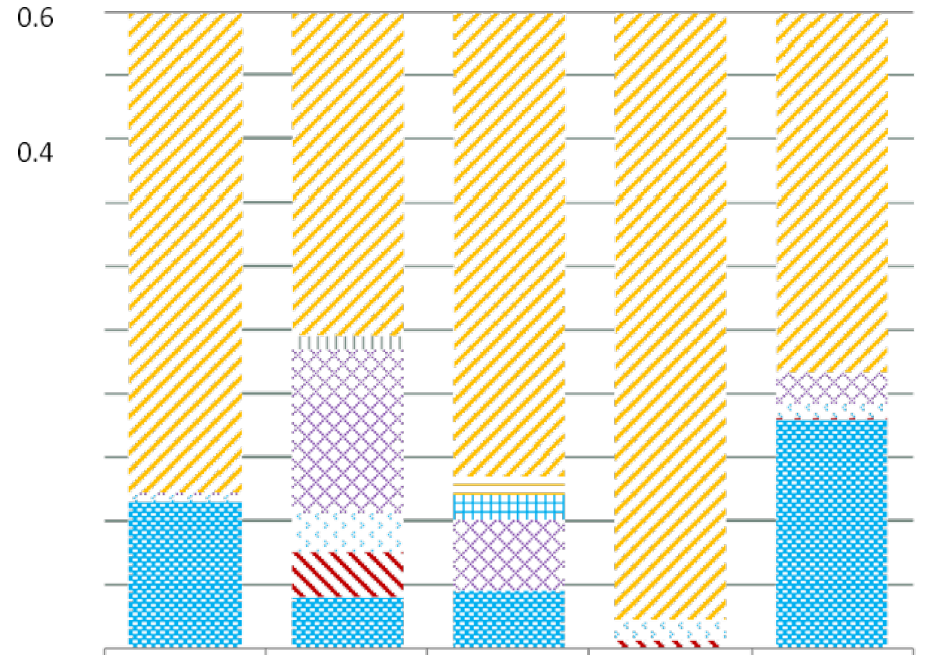


of variation in AMF communities was explained by soil properties (8.0-36.0\%) and by the correlation between soil properties and land use intensity (5.0-26.0\%) than by temporal variation (0.0-6.0\%) and land use intensity per se (0.0-7.0\%). In the case

of Lancaster, by contrast, Bseason^ ${ }^{\wedge}$ explained a higher propor- tion of AMF community variation (3.4\%) than either land use intensity $(1.0 \%)$ or soil properties $(0.0 \%)$. Interestingly, the greatest proportion of variance in AMF communities ex-

plained by intensity and soil/intensity was found at Lusignan. A large amount of AMF community structure var- iance could not be explained, indicating that other variables, which were not measured, were important drivers of AMF communities in the LTO soils under study.

\section{Discussion}

AMF communities in the soils of four sites (LTOs) across Europe were investigated in this study. We identified soil AMF communities on the basis of 454 sequencing of ITS2 amplicons, which has the benefit of incorporating both extraradical hyphae and spores in soil (Hempel et al. 2007; Dumbrell et al. 2010a). Our objectives were to explore the relative contributions of land use intensity, soil physicochem- ical features, and temporal (seasonal) variation to AMF diver- sity and community composition and to identify broadly ap- plicable indicators of land use intensification.

Soil properties differed greatly among the LTO sites and less between land use intensities within sites, and generally the same was true for microbial communities in this study as well as in Thomson et al. (2015). The strongest consistent differ- ences in soil properties were found in Berchidda. In consequence, Thomson et al. (2015) also found the strongest

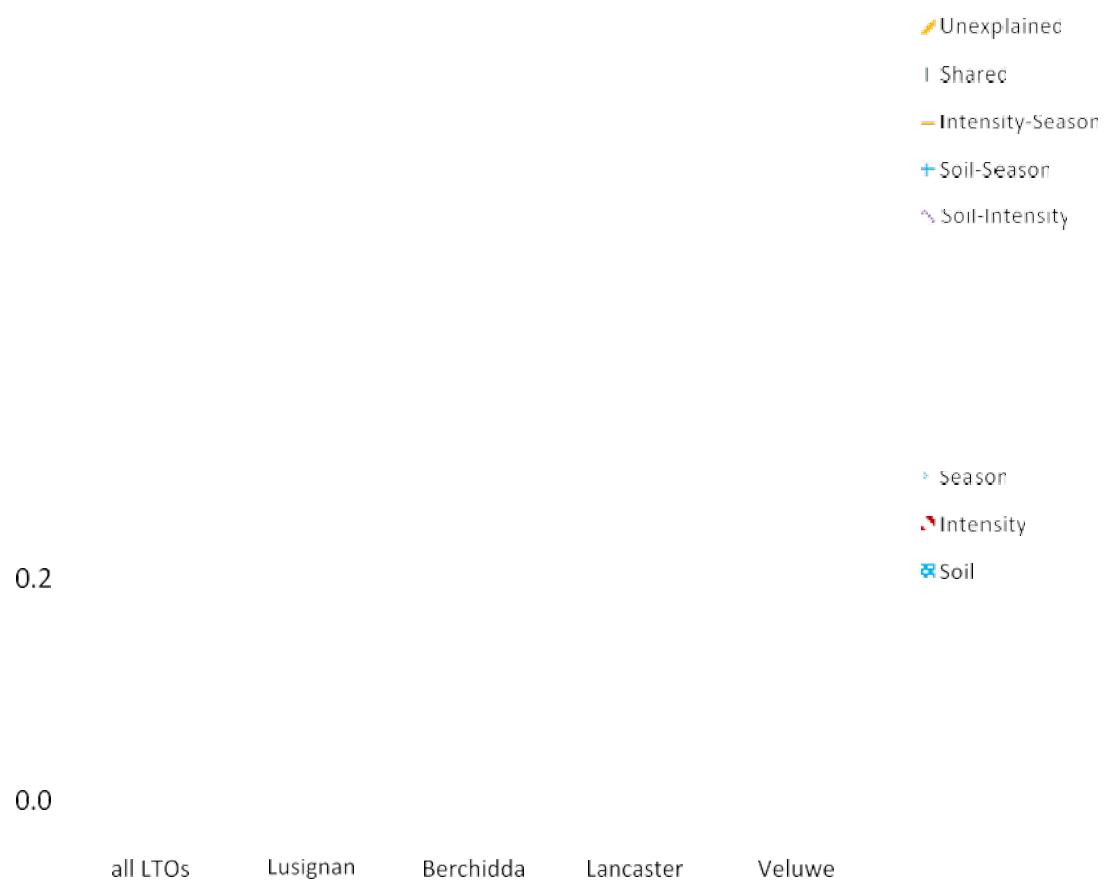


differences in microbial communities out of all sites between Berchidda $\mathrm{H}$ and L, and, interestingly, also the lowest micro- bial diversity. As we did not find the same in the present study, the soil factors differing in Berchidda seemed to be of less importance for AMF than for other microbial communities. Even the transition from an AMF-dominated grassland to a forest/grassland with a strong ectomycorrhizal component in Berchidda apparently did not cause a strong shift in overall AMF community structure. The C/N ratio, which Thomson et al. (2015) stated to be the strongest driver for soil fungal community structure, had a significant effect in our study, but was largely outdone in significance by other factors such as soil texture and $\mathrm{pH}$. This may be explained by the majority of the fungi detected by Thomson et al. (2015) being Asco- and Basidiomycetes, many of which are saprotrophs, while the Glomeromycota are obligate biotrophs.

In the present study, the two different management intensi- ties in Lusignan had the most striking effect on AMF commu- nities, the only site where a grassland was compared to a tilled agricultural rotation. Although not significant, Lusignan also was the site with the strongest effects on AMF richness and Shannon index. This finding is in agreement with numerous other studies, where mechanical disturbance by tillage was identified as the soil management having the most pronounced effects on AMF communities, which is easily explained by the disruption of fungal mycelia by ploughing (Stockinger et al. 2014; Peyret-Guzzon et al. 2016).

At the Berchidda and Lusignan (the only location that in- cluded an arable soil) LTOs, where land use histories strongly differ, the largest proportion of the explained variance in AMF communities was the common fraction between soil proper- ties and land use intensity. These findings suggest that the effects of land use intensification on AMF communities are mediated by corresponding changes in soil parameters.

Similarly, in Northern China, Xiang et al. (2014) found that the land use influence on AMF community composition was mediated by soil properties at a landscape-scale. Hazard et al. (2013), by using Trifolium repens and Lolium perenne bait plants to compare AMF communities in the soil of 40 geo- graphically dispersed sites in Ireland representing different land uses and soil types, found that AMF community compo- sition was influenced by abiotic variables ( $\mathrm{pH}$, rainfall, and soil type), but not land use or geographical distance, suggest- ing that specific environmental variables of sites that differ within land uses have a stronger effect than land use itself on AMF communities. Local effects of land use intensity on AMF community composition also were observed in Estonia between intensive and sustainable land uses (Moora et al. 2014).

That the strongest differences among AMF communities in this study were found among sites which do differ in soil properties could be evidence for soil as a major driver of these differences. However, the sites also were separated by geographical distance, which was shown to play a role in differentiating AMF communities at the European scale (Bouffaud et al. 2016) and were in different climate zones. The latter factors were not specifically analyzed in the present study, as the sampling scheme was not well-adapted for this. Bouffaud et al. (2016) also proposed land use indicator molecular species for soil factors and land use, which were valid throughout their European-scale sampling, but the land use categories used by those authors (forest, grassland, arable land) were much broader than the ones used here.

We found that about half of all molecular taxa we detected were present in all four sites. A recent global-scale sampling in natural and managed sites revealed very low endemism in AMF diversity, 93\% of taxa (the so-called virtual taxaintro- duced by Öpik et al. 2010) being found on multiple continents, 34\% on all six continents surveyed, $90 \%$ in more than one climatic zone, and $79 \%$ in both forests and grasslands (Davison et al. 2015), suggesting that many AMF endure very different 包 springer 
environmental conditions. However, Bruns and Taylor (2016) recently argued that this low level of endemism is likely a consequence of the conservative species definition based on conserved sequenced markers, rather than to ecolog- ical patterns. The question whether ecotypic variation within apparently widespread AMF taxa might exist rarely has been addressed because of a lack of appropriate sequence markers resolving intraspecies genotypes in most species. Evidence for different ecotypes of Rhizophagus irregularis was, however, found by Börstler et al. (2010) using mitochondrial ribosomal large subunit data.

Variance partitioning indicated that the greatest proportion (23\%) of the variation in the AMF community composition explained by the measured variables was attributable to soil properties, indicating a major influence of environmental het- erogeneity. Again, this finding was in agreement with Thomson et al. (2015).

In our study, we certainly have missed some major envi- ronmental predictors of AMF communities. Indeed, most (51.0-95.6\%) community-level variance could not be ex- plained, indicating that other non-measured edaphic and cli- matic parameters may have been important drivers of AMF communities. Furthermore, environmentally independent, sto- chastic events (such as population dynamics due to irregular, unpredictable environmental or demographic fluctuation) can deeply affect AMF assemblages (Lekberg et al. 2007; Dumbrell et al. 2010b; Verbruggen et al. 2012). For instance, Dumbrell et al. (2010b) suggested that chance-events could lead to a positive feedback mechanism (which could be ran- dom) on any taxon in the community. Biotic interactions such as competition also may contribute to shaping community composition (Horn et al. 2014).

Variance partitioning also showed that the influence of tem- poral factors in determining AMF community composition was less strong than soil for three out of the four LTOs. In 
the case of Lancaster, by contrast, season (temporal variation) was the factor accounting for the highest proportion of AMF community variation explained by the factors under study. However, the fraction explained by season was relatively low and almost all community variance remained unexplained in Lancaster. This was probably because in this site, the mea- sured soil variables did not differ considerably between sea- sons and land use intensity levels, and for the little they did, they were not highly correlated with AMF OTU distribution. Hence, for this particular location, neither the categorical nor the measured soil physicochemical variables significantly ex- plained AMF community composition, suggesting that un- measured environmental variables and stochasticityprimarily might be involved in governing the AMF community.

The non-significant effects of temporal variation on AMF communities at Berchidda and Veluwe contrasted with the statistically significant temporal fluctuations of specific AMF orders. Given that these taxonomic groups may exhibit different dynamics, this could lead to dimin- ished significance in the overall dataset. Temporal shifts in AMF communities already have been described in grassland ecosystems (Dumbrell et al. 2011) as well as in semiarid-arid agroecosystems (Bainard et al. 2014) and maple-associated communities (Helgason et al. 2014). By contrast, Santos-Gonzalez et al. (2007) did not observe significant dynamics of AMF communities in a Swedish semi-natural grassland.

As previously mentioned, we also aimed at identifying land use features affecting individual AMF taxa across different soil types and climatic zones. In spite of the different approach and high degree of intensification examined in our work, our study failed to retrieve Buniversal $\wedge$ AMF indicators (individual taxa or combinations of taxa) of land use intensification.

Similar to the absence of an overall effect of land use intensity, this is not surprising, considering the diversity of land uses across the sites. A similar absence of general indicators was reported for bacteria, archaea, and non-AMF fungi in the same soil samples we analyzed (Thomson et al. 2015). Taken together, the results obtained by our group as well as the authors cited above suggest that specific microbial indicators of change in biodiversity are likely to be dependent on local soil and climatic effects and the nature of the land use intensifica- tion (Thomson et al. 2015).

Interestingly, we found numerous significant shifts in rela- tive sequence abundance among glomeromycotan orders among LTOs and land use intensity levels, indicating that quantitative changes may be more powerful indicators for these factors than presence/absence. Changes were most ob- vious in the Paraglomerales in response to season and in Archaeosporales in response to land use intensity level, rais- ing interesting questions concerning the ecological functions of the different orders which may underlie these patterns. As pyrosequencing at best only can deliver an approximate view of taxon abundance, this question would have to be further elucidated by quantitative PCRs or DNA microarray analyses. In conclusion, no overall effect of land use intensification was found across LTOs, while some effects were detected within specific LTOs. We found that an important fraction of AMF community variance was often explained by soil vari- ables or by their correlation with land use intensity level or with season. Therefore, we suggest that alterations of soil features, partly induced by land use intensification, may often play an important role as drivers of AMF community shifts in the soil. In general, the effects of the examined factors on the structure of AMF assemblages are not Buniversal^ (i.e., consistent among LTOs) but may depend on location-specific environmental differences.

Acknowledgments We are grateful to Alberto Orgiazzi (EU- commission, JRC) for his useful suggestions. We warmly acknowledge the LTO leaders and their institutions for experimental facilities and ac- cess to data: P.P. Roggero (University of Sassari, Italy), R. Bardgett (University of Lancaster, 恝 Springer 
United Kingdom), A. Chabbi (INRA, Lusignan, France), R. Finlay (SLU, Uppsala, Sweden), W. van der Putten (NIOO, Wageningen, The Netherlands). This work was supported by the European Commission project EcoFINDERS (FP7-64465; Ecological Function and Biodiversity Indicators in European Soils, http://ecofinders.eu/).

\section{References}

Abarenkov K, Henrik Nilsson R, Larsson K-H, Alexander IJ, Eberhardt U, Erland S, Høiland K, Kjøller R, Larsson E, Pennanen T, Sen R, Taylor AFS, Tedersoo L, Ursing BM, Vrålstad T, Liimatainen K, Peintner U, Kõljalg U (2010) The UNITE database for molecular identification of fungi - recent updates and future perspectives. New Phytol 186:281-285

An GH, Miyakawa S, Kawahara A, Osaki M, Ezawa T (2008) Community structure of arbuscular mycorrhizal fungi associated with pioneer grass species Miscanthus sinensis in acid sulfate soils: habitat segregation along pH gradients. Soil Sci Plant Nutr 54:517- 528

Augé R (2001) Water relations, drought and vesicular-arbuscular mycor- rhizal symbiosis. Mycorrhiza 11:3-42

Azcón-Aguilar C, Barea J (1997) Arbuscular mycorrhizas and biological control of soil-borne plant pathogens-an overview of the mecha- nisms involved. Mycorrhiza 6:457-464

Bagella S, Filigheddu R, Caria MC, Girlanda M, Roggero PP (2014) Contrasting land uses in Mediterranean agro-silvo-pastoral systems generated patchy diversity patterns of vascular plants and below- ground microorganisms. C R Biol 337:717-724

Bai C, He XL, Tang HL, Shan BQ, Zhao LL (2009) Spatial distribution of AMF, glomalin and soil enzymes under the canopy of Astragalus adsurgens pall in the mu US Sandland, China. Soil Biol Biochem 41:942-947

Bainard LD, Bainard JD, Hamel C, Gan Y (2014) Spatial and temporal structuring of arbuscular mycorrhizal communities 
influenced by abiotic factors and host crop in a semi-arid prairie agroecosystem. FEMS Microbiol Ecol 88:333-344

Bainard LD, Koch AM, Gordon AM, Newmaster SG, Thevathasan NV, Klironomos JN (2011) Influence of trees on the spatial structure of arbuscular mycorrhizal communities in a temperate tree-based intercropping system. Agric Ecosyst Environ 144:13-20

Berger SA, Krompass D, Stamatakis A (2011) Performance, accuracy, and web server for evolutionary placement of short sequence reads under maximum likelihood. Syst Biol 60:291-302

Borriello R, Lumini E, Girlanda M, Bonfante P, Bianciotto V (2012) Effects of different management practices on arbuscular mycorrhizal fungal diversity in maize fields by a molecular approach. Biol Fertil Soils 48:911-922

Börstler B, Thiéry O, Sýkorová Z, Berner A, Redecker D (2010) Diversity of mitochondrial large subunit rDNA haplotypes of glo- mus intraradices in two agricultural field experiments and two seminatural grasslands. Mol Ecol 19:1497-1511

Bouffaud M-L, Creamer R, Stone D, Plassart P, van Tuinen D, Lemanceau P, Wipf D, Redecker D (2016) Indicator species and co-occurrence in communities of arbuscular mycorrhizal fungi at the European scale. Soil Biol Biochem 103:464-470

Bruns TD, Taylor JW (2016) Comment on Bglobal assessment of arbuscular mycorrhizal fungus diversity reveals very low endemism^^. Science 351:826

Ciccolini V, Bonari E, Pellegrino E (2015) Land-use intensity and soil properties shape the composition of fungal communities in Mediterranean peaty soils drained for agricultural purposes. Biol Fertil Soils 51:719-731

Ciesielsky H, Sterckeman T (1997) Determination of cation exchange capacity and exchangeable cations in soils by means of cobalt hexamine trichloride. Effects of experimental condictions. Agronomie 17:1-7

Dai M, Bainard LD, Hamel C, Gan Y, Lynch D (2013) Impact of land use on arbuscular mycorrhizal fungal communities in rural Canada. Appl Environ Microbiol 79:6719-6729

Davison J, Moora M, Öpik M, Adholeya A, Ainsaar L, Bâ A, Burla S, Diedhiou AG, Hiiesalu I et al (2015) Global assessment of arbuscular mycorrhizal fungus diversity reveals very low endemism. Science 349:970-973

De Cáceres M, Legendre P (2009) Associations between species and groups of sites: indices and statistical inference. Ecology 90:3566- 3574

De Cáceres M, Legendre P, Wiser SK, Brotons L (2012) Using species combinations in indicator value analyses. Methods Ecol Evol 3: 973-982

Drigo B, Pijl AS, Duyts H, Kielak AM, Gamper HA, Houtekamer MJ (2010) Shifting carbon flow from roots into associated microbial communities in response to elevated atmospheric CO2. PNAS 107: 10938-10942

Dufrene M, Legendre P (1997) Species assemblages and indicator spe- cies: the need for a flexible asymmetrical approach. Ecol Monogr 67:345-366

Dumbrell AJ, Ashton PD, Aziz N, Feng G, Nelson M, Dytham C, Fitter AH, Helgason T (2011) Distinct seasonal assemblages of arbuscular mycorrhizal fungi revealed by massively parallel pyrosequencing. New Phytol 190:794-804

Dumbrell AJ, Nelson M, Helgason T, Dytham C, Fitter AH (2010a) Relative roles of niche and neutral processes in structuring a soil microbial community. ISME J 4:337-345

Dumbrell AJ, Nelson M, Helgason T, Dytham C, Fitter AH (2010b) Idiosyncrasy and overdominance in the structure of natural commu- nities of arbuscular mycorrhizal fungi: is there a role for stochastic processes? J Ecol 98:419-428

Edgar RC (2010) Search and clustering orders of magnitude faster than BLAST. Bioinformatics 26:2460- 
Fierer N, Ladau J, Clemente JC, Leff JW, Owens SM, Pollard KS, Knight JA, McCulley RL (2013) Reconstructing the microbial diversity and function of pre-agricultural tallgrass prairie soils in the United States. Science 342:621-624

Fitter AH, Gilligan CA, Hollingworth K, Kleczkowski A, Twyman RM, Pitchford JW (2005) Biodiversity and ecosystem function in soil. Funct Ecol 19:369-377

Fitter AH, Helgason T, Hodge A (2011) Nutritional exchanges in the arbuscular mycorrhizal symbiosis: implications for sustainable agri- culture. Fungal Biol Rev 25:68-72

Fitzsimons MS, Miller RM, Jastrow JD (2008) Scale-dependent niche axes of arbuscular mycorrhizal fungi. Oecologia 158:117-127

Hazard C, Gosling P, van der Gast CJ, Mitchell DT, Doohan FM, Bending GD (2013) The role of local environment and geographical distance in determining community composition of arbuscular mycorrhizal fungi at the landscape scale. ISME J 7:498-508

Helgason T, Daniell TJ, Husband R, Fitter AH, Young JP (1998) Ploughing up the wood-wide web? Nature 394:431

Helgason T, Feng H, Sherlock DJ, Young JPW, Fitter AH (2014) Arbuscular mycorrhizal communities associated with maples (Acer spp.) in a common garden are influenced by season and host plant. Botany 92:321-326

Hempel S, Renker C, Buscot F (2007) Differences in the species compo- sition of arbuscular mycorrhizal fungi in spore, root and soil com- munities in a grassland ecosystem. Environ Microbiol 9:1930-1938 Hildebrandt U, Regvar M, Bothe H (2007) Arbuscular mycorrhiza and heavy metal tolerance. Phytochemistry 68:139-146

Hoeksema JD, Chaudhary VB, Gehring CA, Johnson NC, Karst J, Koide RT, Pringle A, Zabinski C, Bever JD, Moore JC, Wilson GWT, Klironomos JN, Umbanhowar J (2010) A meta-analysis of context-dependency in plant response to inoculation with mycorrhi- zal fungi. Ecol Lett 13:394-407

Horn S, Caruso T, Verbruggen E, Rillig MC, Hempel S (2014) Arbuscular mycorrhizal fungal communities are phylogenetically clustered at small scales. ISME J 8:2231-2242

Ihrmark K, Bödeker ITM, Cruz-Martinez K et al (2012) New primers to amplify the fungal ITS2 region - evaluation by 454-sequencing of artificial and natural communities. FEMS Microbiol Ecol 82:666- 677

Jansa J, Erb A, Oberholzer HR, Smilauer P, Egli S (2014) Soil and geog- raphy are more important determinants of indigenous arbuscular mycorrhizal communities than management practices in Swiss agri- cultural soils. Mol Ecol 23:2118-2135

Kardol P, Bezemer TM, van der Wal A, van der Putten WH (2005) Successional trajectories of soil nematode and plant communities in a chronosequence of ex-arable lands. Biol Cons 126:317-327

Krüger M, Stockinger H, Krüger C, Schüßler A (2009) DNA-based spe- cies level detection of Glomeromycota: one PCR primer set for all arbuscular mycorrhizal fungi. New Phytol 183:212-223

Lekberg Y, Koide RT, Rohr JR, Aldrich-Wolfe L, Morton JB (2007) Role of niche restrictions and dispersal in the composition of arbuscular mycorrhizal fungal communities. J Ecol 95:95-105

Lekberg Y, Koide RT (2005) Is plant performance limited by abundance of arbuscular mycorrhizal fungi? A meta-analysis of studies pub- lished between 1988 and 2003. New Phytol 168:189-204

Li T, Hu YJ, Hao ZP, Li H, Wang YS, Chen BD (2013) First cloning and characterization of two functional aquaporin genes from an arbuscular mycorrhizal fungus Glomus intraradices. New Phytol 197:617-630

Lin X, Feng Y, Zhang H, Chen R, Wang J, Zhang J et al (2012) Long-term balanced fertilization decreases arbuscular mycorrhizal fungal diver- sity in an arable soil in North China revealed by 454 pyrosequenc- ing. Environ Sci Technol 46:5764-5771

Liu Y, Shi G, Mao L, Cheng G, Jiang S, Ma X et al (2012) Direct and indirect influences of 8 years of nitrogen and phosphorus 
fertilization on Glomeromycota in an alpine meadow ecosystem. New Phytol 194:523-535

Lumini E, Orgiazzi A, Borriello R, Bonfante P, Bianciotto V (2010) Disclosing arbuscular mycorrhizal fungal biodiversity in soil through a land-use gradient using a pyrosequencing approach. Environ Microbiol 12:2165-2179

Moebius-Clune DJ, Anderson ZU, Pawlowska TE (2013) Arbuscular mycorrhizal fungi associated with a single agronomic plant host across the landscape: the structure of an assemblage. Soil Biol Biochem 64:181-190

Moora M, Davison J, Öpik M, Metsis M, Saks U, Jairus T et al (2014) Anthropogenic land use shapes the composition and phylogenetic structure of soil arbuscular mycorrhizal fungal communities. FEMS Microbiol Ecol 90:609-621

Morris EK, Buscot F, Herbst C, Meiners T, Obermaier E, Wäschke NW et al (2013) Land use and host neighbor identity effects on arbuscular mycorrhizal fungal community composition in focal plant rhizosphere. Biodivers Conserv 22:2193-2205

Mummey DL, Rillig MC (2006) The invasive plant species Centaurea maculosa alters arbuscular mycorrhizal fungal communities in the field. Plant Soil 288:81-90

Nilsson RH, Veldre V, Hartmann M, Unterseher M, Amend A, Bergsten J, Kristiansson E, Ryberg M, Jumpponen A, Abarenkov K (2010) An open source software package for automated extraction of ITS1 and ITS2 from fungal ITS sequences for use in high-throughput community assays and molecular ecology. Fungal Ecol 3:284-287

Oehl F, Laczko E, Bogenrieder A, Stahr K, Bösch R, van der Heijden M et al (2010) Soil type and land use intensity determine the compo- sition of arbuscular mycorrhizal fungal communities. Soil Biol Biochem 42:724-738

Oksanen J, Blanchet F, Kindt GR, Legendre P, Minchin PR, O'Hara RB, et al. (2013) vegan: Community ecology package. URL http://cran. r-project.org/package=vegan

Olsen SR (1954) Estimation of available phosphorus in soils by extrac- tion with sodium bicarbonate. Circ US Dep Agric 939:1-9

Öpik M, Vanatoa A, Vanatoa E, Moora M, Davison J, Kalwij JM, Reier Ü, Zobel M (2010) The online database MaarjAM reveals global and ecosystemic distribution patterns in arbuscular mycorrhizal fungi(Glomeromycota). New Phytol 188:223-241

Orgiazzi A, Lumini E, Nilsson RH, Girlanda M, Vizzini A, Bonfante P, Bianciotto V (2012) Unravelling soil fungal communities from dif- ferent Mediterranean land-use backgrounds. PLoS One 7:e34847

Pereira ESMC, Schloter-Hai B, Schloter M, van Elsas JD, Salles JF (2013) Temporal dynamics of abundance and composition of nitrogen-fixing communities across agricultural soils. PLoS One 8: e74500

Peyret-Guzzon M, Stockinger H, Bouffaud M-L, Farcy P, Wipf D, Redecker D (2016) Arbuscular mycorrhizal fungal communities and Rhizophagus irregularis populations shift in response to shortterm ploughing and fertilisation in a buffer strip. Mycorrhiza 24:33- 46

Plassart P, Terrat S, Thomson B, Griffiths R, Dequiedt S, Lelievre M et al (2012) Evaluation of the ISO standard 11063 DNA extraction pro- cedure for assessing soil microbial abundance and community struc- ture. PLoS One 7:e44279

R development core team (2013) R: A language and environment for statistical computing. Vienna, Austria: R Foundation for statistical computing. ISBN 3-900051-07-0. URL http://wwwR-project.org/ Ordovician. Science 289:1920-1921

Redecker D, Kodner R, Graham LE (2000) Glomalean fungi from the

Redecker D, Schüßler A, Stockinger H, Stürmer SL, Morton JB, Walker C (2013) An evidence-based consensus for the classification of arbuscular mycorrhizal fungi (Glomeromycota). Mycorrhiza 23: 515-531

Springer 
Santos-Gonzalez JC, Finlay RD, Tehler A (2007) Seasonal dynamics of arbuscular mycorrhizal fungal communities in roots in a seminatural grassland. Appl Environ Microbiol 73:5613-5623

Schloss PD, Westcott SL, Ryabin T, Hall JR, Hartmann M, Hollister EB et al (2009) Introducing mothur: open-source, platform-indepen- dent, community-supported software for describing and comparing microbial communities. Appl Environ Microbiol 75:7537-7541

Schnoor TK, Lekberg Y, Rosendahl S, Olsson PA (2011) Mechanical soil disturbance as a determinant of arbuscular mycorrhizal fungal com- munities in semi-natural grassland. Mycorrhiza 21:211-220

Schüßler A, Walker C (2010) The Glomeromycota: a species list with new families and new genera. URL www.amf-phylogeny.com.

Seddaiu G, Porcu G, Ledda L, Roggero PP, Agnelli A, Corti G (2013) Soil organic matter content and composition as influenced by soil management in a semi-arid Mediterranean agro-silvo-pastoral system. Agriculture Ecosystems Environ 167:1-11

Smith S, Read DJ (2008) Mycorrhizal symbiosis, 3rd edn. Academic Press, London

Spurgeon DJ, Keith AM, Schmidt O, Lammertsma DR, Faber JH (2013) Land-use and landmanagement change: relationships with earth- worm and fungi communities and soil structural properties. BMC Ecol 13:46

Stockinger H, Krüger M, Schüßler A (2010) DNA barcoding of arbuscular mycorrhizal fungi. New Phytol 187:461-474. doi:10.1111/j.1469-8137.2010.03262.x

Stockinger H, Peyret-Guzzon M, Koegel S, Bouffaud M-L, Redecker D (2014) The largest subunit of RNA polymerase II as a new marker gene to study assemblages of arbuscular mycorrhizal fungi in the field. PLoS One 9:e107783

Thomson BC, Tisserant E, Plassart P, Uroz S, Griffiths RI, Hannula E, Buée M, Mougel C, Ranjard L, Van Veen JA, Martin F, Bailey MJ, Lemanceau P (2015) Soil conditions and land use intensification effects on soil microbial communities across a range of European field sites. Soil Biol Biochem 88:403-413

Turrini A, Giovannetti M (2012) Arbuscular mycorrhizal fungi in nation- al parks, nature reserves and protected areas worldwide: a strategic perspective for their in situ conservation. Mycorrhiza 22:81-97

Valyi K, Rillig MC, Hempel S (2015) Land use intensity and host plant identity interactively shape communities of arbuscular mycorrhizal fungi in roots of grasssland plants. New Phytol 205:15771586

van der Gast CJ, Gosling P, Tiwari B, Bending GD (2011) Spatial scaling of arbuscular mycorrhizal fungal diversity is affected by farming practice. Environ Microbiol 13:241-249

van der Heijden M, Klironomos J, Ursic M, Moutoglis P, Streitwolf- Engel R, Boller T, Wiemken A, Sanders IR (1998) Mycorrhizal fungal diversity determines plant biodiversity, ecosystem variability and productivity. Nature 74:69-72

van der Heijden M, Scheublin TR (2007) Functional traits in mycorrhizal ecology: their use for predicting the impact of arbuscular mycorrhi- zal fungal communities on plant growth and ecosystem functioning. New Phytol 174:244-250

Van Geel M, Ceustermans A, van Hemelrijck W, Lievens B, Honnay O (2015) Decrease in diversity and changes in community composi- tion of arbuscular mycorrhizal fungi in roots of apple trees with increasing orchard management intensity across a regional scale. Mol Ecol 24:941-952

Verbruggen E, van der Heijden M, Weedon JT, Kowalchuk G, Röling WFM (2012) Community assembly, species richness and nestedness of arbuscular mycorrhizal fungi in agricultural soils. Mol Ecol 21: 2341-2353

Verbruggen E, Xiang D, Chen B, Xu T, Rillig MC (2015) Mycorrhizal fungi associated with high soil $\mathrm{N}: \mathrm{P}$ ratios are more likely to be lost upon conversion from grasslands to arable agriculture. Soil Biol Biochem 86:1-4

White T, Brun T, Lee S, Taylor J (1990) Amplification and direct se- quencing of fungal ribosomal RNA genes for phylogenetics. In: 
Innis M, Gelfand D, Sninsky J, White T (eds) PCR protocols: a guide to methods and applications. Academic Press, New York, pp. 315-322

Wickham H (2009) ggplot2: elegant graphics for data analysis. New York: Springer. URL http://had.co.nz/ggplot2/book

Xiang D, Verbruggen E, Hu Y, Veresoglou SD, Rillig MC, Zhou W et al (2014) Land use influences arbuscular mycorrhizal fungal 
communities in the farming-pastoral ecotone of northern China. New Phytol 204:968-978

Zhang L, Zhang J, Christie P, Li X (2009) Effect of inoculation with the arbuscular mycorrhizal fungus Glomus intraradices on the root-knot nematode Meloidogyne incognita in cucumber. J Plant Nutr 32:967- 979 